\title{
STUDY OF CHARACTERISTICS OF PARTIAL REPLACEMENT OF PHENOL BY COCONUT SHELL FLOUR IN A PHENOL FORMALDEHYDE RESIN
}

\author{
S.S. Inamdar ${ }^{1}$, Kiran kumar Rathod ${ }^{2}$ \\ ${ }^{1,2}$ Assistant Professor, Department of Chemical Engineering SDM College of Engineering and Technology, \\ DHARWAD- 580 002, Karnataka, India,nasi_chem@rediffmail.com,kiri.rathod @gmail.com
}

\begin{abstract}
Phenol formaldehyde (PF) resins are usually synthetic polymer resins, based on the condensation reaction of formaldehyde with phenol. Phenol being a vital component is rarely available now and the cost of which influences the cost of the adhesive. An alternative, cheaper source of Phenol would be of great interest to all users of PF resin. World wide shortage, increase in price and future supplies of phenol for the wood based panel industries have renewed the interest in finding partial or full substitutes based on non-petroleum resources for synthetic resin adhesives. Since wood materials like flours of sal, teak, coconut etc. contain ligno cellulosic materials; can be used for the partial replacement of phenol in phenolic adhesives.

In the present investigation, an attempt has been made to develop and study the characteristics of a new resin synthesized by using coconut shell flour as a partial replacement for phenol in a phenol formaldehyde resin. Coconut Shell Flour (CSF) being comparatively cheaper, indigenously available, is renewable phenolic raw material and is found to be effective for partial replacement. Resin adhesive prepared from CSF of particle size $-150+250$ was found to be suitable. The effect of partial replacement on properties of the resulting resin viz. tensile strength, effect of $\mathrm{pH}$ on polymerization time, morphology using Wide angle X-ray diffraction, SEM images of the surface morphology of pure phenol formaldehyde resin and CSF embedded resin material were investigated by scanning electron microscopy (SEM) at $10 \mathrm{kV}$ with a JEOL (Japan) JSM-840A scanning electron microscope. Investigations revealed that 40-50\% of phenol can be replaced by using CSF.
\end{abstract}

Keywords: Coconut Shell Flour CSF, Phenolic, Adhesive, Partial replacement, Tensile strength, Wide angle XRD. ***

\section{INTRODUCTION}

Phenol-formaldehyde resin adhesive is available in India at about Rs.30. The market worldwide is million tons per annum which doubles every 10 years. In India alone the phenol formaldehyde resin adhesive industry has a turnover of about Rs. 800 crore per annum. Phenol is imported in India resulting in precious foreign exchange reserves being used up. Benzene from which phenol is made has been under pressure to make other organic compounds like cumene, styrene, xylene, toluene as well as detergents and polymers etc. Hence worldwide scarcity of phenol has resulted. Decreasing phenol consumption by using suitable substitute boosts up India's foreign exchange reserves. Saving precious foreign exchange for the country is the priority.

Phenol formaldehyde resin adhesive, which is commercially used, is expected to have the following specifications.

Viscosity: 300 to 4000 centipoises; curing temperature: $143^{\circ} \mathrm{C}$; nature is basic; physical state: black uniform slurry without any setting even after being kept undisturbed for a long time.
Important uses of phenol formaldehyde resin are in the manufacture of exterior grade Douglas fir plywood, particle board, grits, fiber boards, glass-fiber mats, laminates, automotive parts, construction and electrical applications.

There is no ideal adhesive and it is doubtful that there will ever be such a product because of conflicting requirements. Many bonding requirements are for permanent structure adhesives, but many temporary or demountable adhesives, such as masking tapes, can be easily removed. Low viscosity is required when the adhesive must penetrate small cracks or be used in very thin bond lines, but heavy bodied or thixotropic adhesives are required to fill gaps and resist sag in vertical applications. Many adhesives must have fast garb or tack, but must be easily repositionable for a controlled time prior to the tacky stage. Adhesives must readily wet the bonding area, but not bleed out and contaminate areas not be bonded. Heat-curing adhesives should cure at low temperatures, but have unlimited shelf stability at temperature normally attained in transportation and storage. They should remain flexible at cryogenic temperatures, but not creep at elevated temperatures. Adhesives should be easy to apply and 
require no special application or fixturing equipment. They should also be able to bond through oil or other contamination to all solid materials and be available at low cost. Also there are other types of synthetic resin adhesives viz. Urea formaldehyde (UF), Melamine formaldehyde (MF) in addition to Phenol formaldehyde resins. Urea formaldehyde resins are available in liquid or powder form and are probably the most widely used thermosetting adhesive for wood, particularly for the manufacture of plywood and particle board. Unmodified urea-resin glue lines are colorless and have high water and moisture resistance. Melamine, added either in monomeric form or co-reacted with formaldehyde noticeably improve UF glue-bond durability. Resorcinol provides effective fortification for UF resin, though excess of formaldehyde may affect pot life of adhesive mixtures. The higher cost resorcinol restricts its use as a fortifier for UF resins. Melamine formaldehyde adhesives are colorless and are used as hot press adhesives. They have considerable resistance to water and heat and are more weather resistant than the UFs. Their high cost and high temperature curing requirements limit the use of the straight MF to a few special applications. Combination of MF and UF resin are also available. UF resin modification of MFs reduce their cost but with corresponding reduction in durability.

PF resin adhesives are dark red and are available as liquids, powders and in film form. PF resins compounded with fillers and accelerators give high bond strength under all conditions of exposure when properly used. Long time weathering tests have proved their ability to withstand most severe conditions with deterioration. The highest specifications for plywood and particle board make the use of phenolic adhesive almost mandatory. PF resins adhesive set at a hot press temperature of $120^{\circ} \mathrm{C}$ or higher. Phenol-resorcinol resin, Epoxy resin and Polyurethane resin are some more types of thermosetting synthetic adhesives.

There are some physical and chemical factors that influence the adhesive action and are:

\section{Surface Tension:}

A liquid adhesive is suitable for an adhered surface if it can wet that particular surface. The wetting tendency of a liquid adhesive depends on factors like surface tension and viscosity. The attraction between the liquid adhesive and the adhered surface is maximum when the interfacial tension between the two is minimum.

\section{Porosity and smoothness of the contacting surfaces:}

Porosity and smoothness of the surface may be advantageous or non-advantageous depending on the material of surface and properties of adhesives. In some cases porous surfaces help for developing strong joint and in some cases it may form weak joints.

\section{Thickness of the adhesive film:}

Highly viscous adhesives tend to produce thick film with too many voids which posses poor adhesive strength.

Chemical factors are mentioned below.

\section{Polar characteristics of adhesives:}

Polar group containing adhesives are strongly adsorbed by organic contacting surfaces. On the other hand non-polar polymeric adhesives exhibit poor bond strength for such surfaces.

\section{Degree of polymerization:}

The semisolid fraction of a resin exhibits more adhesive strength than highly cured tough fraction. Thus for maximum bond strength of an adhesive its degree of polymerization should lie in a range between unpolymerized fractions.

\section{Effect of pH:}

It has been found that presence of strong acids and alkalis are harmful to the adhesive bond strength. Hence proper $\mathrm{pH}$ should be maintained as per requirements depending on the nature of adhesive.

\section{PROCESS SELECTION}

Coconut shell flour is more suitable as a partial substitute for phenol. CSF takes less acid for its dispersion in the presence of phenol. The salts produced during subsequent processing are therefore less in the case of CSF. It should be advantageous to neutralize sulfuric acid used for dispersing CSF and wood flour with lime or calcium carbonate. CSF can be dispersed with dilute alkali for reaction with formaldehyde. It also appears possible to replace a higher proportion of phenol than reported in this work with but not with wood flour. CSF can be used only up to $40 \%$. Assuming that the lignin and pentosans in the lignocellulosic material take part in the resin forming reaction, the proportion of non-reacting cellulosic materials would be less in the case of CSF.
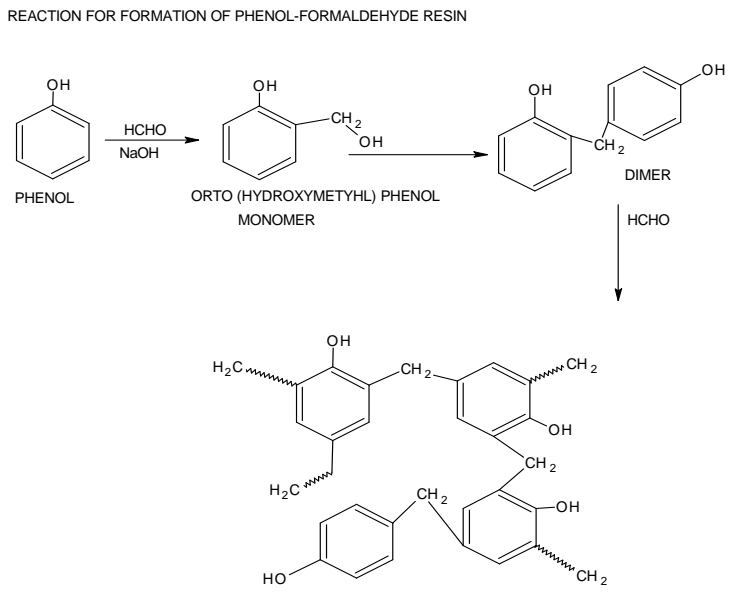

POLYMER 


\begin{tabular}{|l|l|l|l|}
\hline Trial & $\begin{array}{l}\text { Quantity } \\
\text { of } \\
\text { Phenol }(\mathrm{ml})\end{array}$ & $\begin{array}{l}\text { Quantity of } \\
\text { Formaldehyde }(\mathrm{ml})\end{array}$ & $\begin{array}{l}\text { Quantity } \\
\text { of } \\
\mathrm{NaOH}(\mathrm{gm})\end{array}$ \\
\hline 1 & 200 & 370.0 & 16.0 \\
\hline 2 & 50.0 & 92.5 & 4.0 \\
\hline 3 & 54.0 & 95.0 & 4.0 \\
\hline
\end{tabular}

\subsection{Chemistry of Polymerization}

The active positions on the phenol molecule are two ortho and one para positions. When more than one mole of formaldehyde is reacted with one mole of phenol in the presence of alkaline catalyst, ortho (hydroxy methyl) phenol monomer is obtained. The mono methylol phenol immediately reacts with another mole of phenol to form dihydroxyldiphenyl methane. Further heating of these initial reaction products results in condensation and an increase in molecular weight. Condensation takes place between two methylol groups to form methylene. The amount of heating determines the final form of product. Chemistry of the reaction depends on time, temperature, $\mathrm{pH}$, and mole ratio of formaldehyde to phenol.

\section{MATERIALS AND METHODS}

Phenol formaldehyde resin was synthesized in the laboratory to use it as a reference for further investigation. Apparatus and accessories employed were three-neck round bottom flask, Leibig's condenser, thermometers, water bath, beakers, burners, and motor with stirring arrangement. The reagents employed were phenol, sodium hydroxide, formalin $(37 \%$ formaldehyde), in addition to water.

\subsection{Experimental Procedure:}

Phenol was heated to $65^{\circ} \mathrm{C}$ to use it in a molten state, as phenol at room temperature is in crystal form. The chemicals were weighed and taken in different beakers as follows.

Phenol at $65^{\circ} \mathrm{C}, 200 \mathrm{ml}$; formalin at room temperature, 370 $\mathrm{ml}$; $\mathrm{NaOH}$ at room temperature, $16 \mathrm{~g}$; water at room temperature, $25 \mathrm{ml}$.

Phenol to Formaldehyde ratio (mole ratio) was $1: 2 . \mathrm{NaOH}$ was used as a catalyst. All these were taken in a 3 necked round bottom flask. There was no reaction occurring in the beginning. A stirrer was placed for mixing and ensured uniform reaction. The flask was then placed in a water bath. The bath was heated and the reaction mixture was simultaneously stirred. When the mixture reached $65^{\circ} \mathrm{C}$, slowly reaction started. As the reaction is exothermic, heat liberated. The temperature of the mixture was raised to $85^{\circ} \mathrm{C}$ and maintained constantly thereafter. Vapors were condensed and refluxed in the flask. This also helped in maintaining the temperature. The reaction was carried out for a period of 90 minutes. The conversion efficiency achieved was $99 \%$. The resulting resin was decanted in a pan and was allowed to cool for over 2 hours.

The following table gives the details of the trials taken with amount of each component added.

\subsection{Preparation of CSF:}

The used coconut shells which are thrown out as a waste were collected. These were cleaned mechanically to remove dust, fibers and unwanted materials. Then dried in sunlight for a period of $3-4$ hours to remove the maximum moisture and later kept in oven maintained at a temperature of $140-150^{\circ} \mathrm{C}$ for a period of 1 hour. Further, using Jaw crusher and Ball mill fine powder was obtained which contained different particle sizes of CSF. Then using sieve shaker different particle sizes of CSF were fractionated.

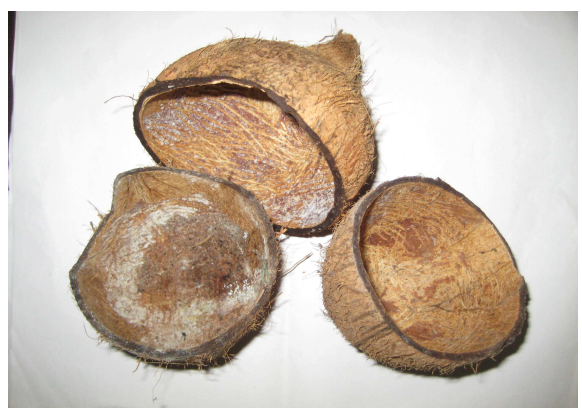

Fig-1: (a) Coconut shells (before)

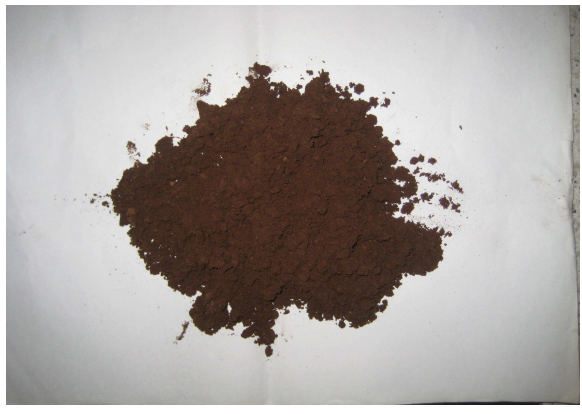

Fig-1: (b) Coconut shell flour (after)

\section{PARTIAL REPLACEMENT OF PHENOL BY}

\section{CSF}

The partial replacement of phenol was brought about by reducing the percentage of phenol in the feed and replacing the amount with CSF. Initially sulfuric acid was used to extract lignin from CSF which produced a pasty mass. Further treatment resulted in a resin with almost the same properties as the original PF resin.

$\begin{array}{lcc}\text { Moisture } & - & 8.00 \\ \text { Ash } & - & 0.6 \\ \text { Lignin } & - & 4.2\end{array}$




$\begin{array}{lll}\text { Cellulose } & - & 26.6 \\ \text { Pentosans } & - & 27.7\end{array}$

\section{PREPARATION OF RESIN ADHESIVE}

Various formulations were tried out to find an optimum percentage of CSF to replace phenol.

\section{Method 1:}

150 parts of phenol was mixed with 10 parts of concentrated sulfuric acid. The mixture was heated to a temperature of 80 to $85^{\circ} \mathrm{C}$. 100 parts of CSF was added with constant mixing. The temperature was then raised to 103 to $105{ }^{\circ} \mathrm{C}$ for a period of 15 minutes in a water bath. The rise caused the mixture to form a pasty mass. This was because of pentosans being converted to furfuraldehyde. Cellulose was broken down to simpler monomers. The reaction was exothermic and heat liberated. The paste was then dispersed into a beaker containing a solution of 25 parts of $\mathrm{NaOH}$ in 200 parts of water while viscosity decreased. This dispersion was then condensed with 370 parts of formaldehyde for 90 minutes at $75^{\circ} \mathrm{C}$. The resulting resin was cooled to room temperature and stored.

\section{Method 2:}

The calculated amount of phenol was mixed with $\mathrm{NaOH}$ solution to a get a white color solution. A known quantity of $\mathrm{CSF}$ was added to the reaction mixture. This reaction mixture was heated to a temperature of $60-70^{\circ} \mathrm{C}$ for a period of 30 minutes in a water bath equipped with a constant stirring arrangement. The temperature was raised to $75-80{ }^{\circ} \mathrm{C}$ for a period of 15 minutes in a water bath. The rise caused the mixture to form a pasty mass. The mixture was then heated to a temperature $85-90^{\circ} \mathrm{C}$ for a period of 90 minutes. 1-2 drops of sulfuric acid was added to the reaction mixture. A known quantity of formaldehyde was further added to the reaction mixture. The mixture was maintained at constant temperature. The resulting resin was cooled to room temperature and stored.

\section{RESULTS AND DISCUSSION}

\subsection{Effect of CSF composition:}

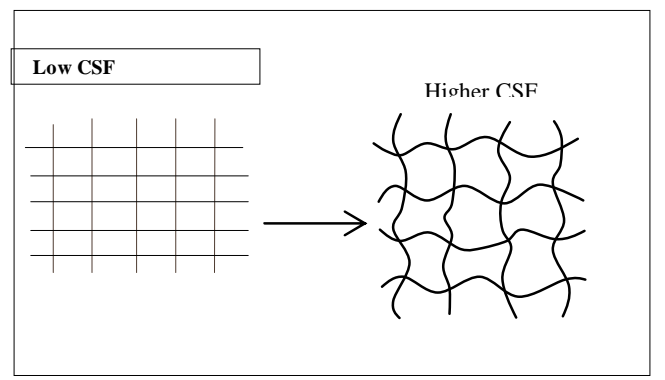

Initially the structure of the resin without the addition of CSF i.e. no CSF or very low CSF concentration showed the homogeneous structure. When the CSF was added, polymerization started and affected the structure of the resin giving more ductility, toughness and flexibility as shown above.

\subsection{Wide Angle X-Ray Diffraction:}

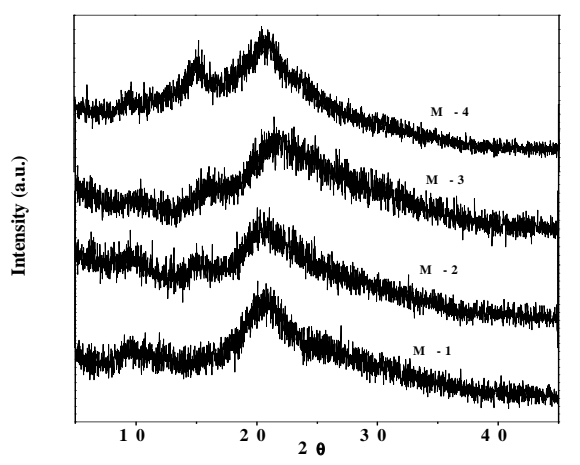

Fig-3: Pattern suggested by Wide Angle X-Ray Diffraction

The morphology of the pure resin and its CSF loaded material was studied at room temperature using a Brucker's D-8 advanced wide-angle $\mathrm{X}$-ray diffractometer. The $\mathrm{X}$-ray source was nickel-filtered $\mathrm{Cu}-\mathrm{Kr}$ radiation $(40 \mathrm{kV}, 30 \mathrm{~mA})$. The dried material membrane was mounted on a sample holder and scanned in the reflection mode at an angle $2 \theta$ over a range from 5 to 450 at a speed of $8 \mathrm{o} / \mathrm{min}$. The patterns thus obtained are presented in the above figure. The X-ray diffraction studies not only indicated the nature of the compounds but also enabled the identification of the space between the clusters of the polymer chains. Pure resin exhibited two peaks at around 10 and $20^{\circ}$ in the diffraction pattern, and is due to the existence of flexible and crystalline regions, respectively.

In case of CSF embedded material, in addition to the peaks appeared at around 10 and $20 \mathrm{o}$, a new peak was observed at around 160 in the diffraction patterns, and the intensity of this proportionately increased with increased CSF loading. This clearly indicated that the CSF loading into resin increased the presence of crystalline regions. Moreover the intensity of the peak appeared at around 160 increased gradually with increasing the CSF addition. This is because of increased crystalline domains in the matrix. All these resulted to improve ductility and toughness of resin material. This was further supported by the calculated d-spacing values of inter segmental spacing, which increased from 6.31 to 6.55 Ao, signifying that upon increasing the CSF loading the crystallinity of the material increased.

Fig-2: Effect of composition of CSF 
Images from Scanning Electron Microscope:

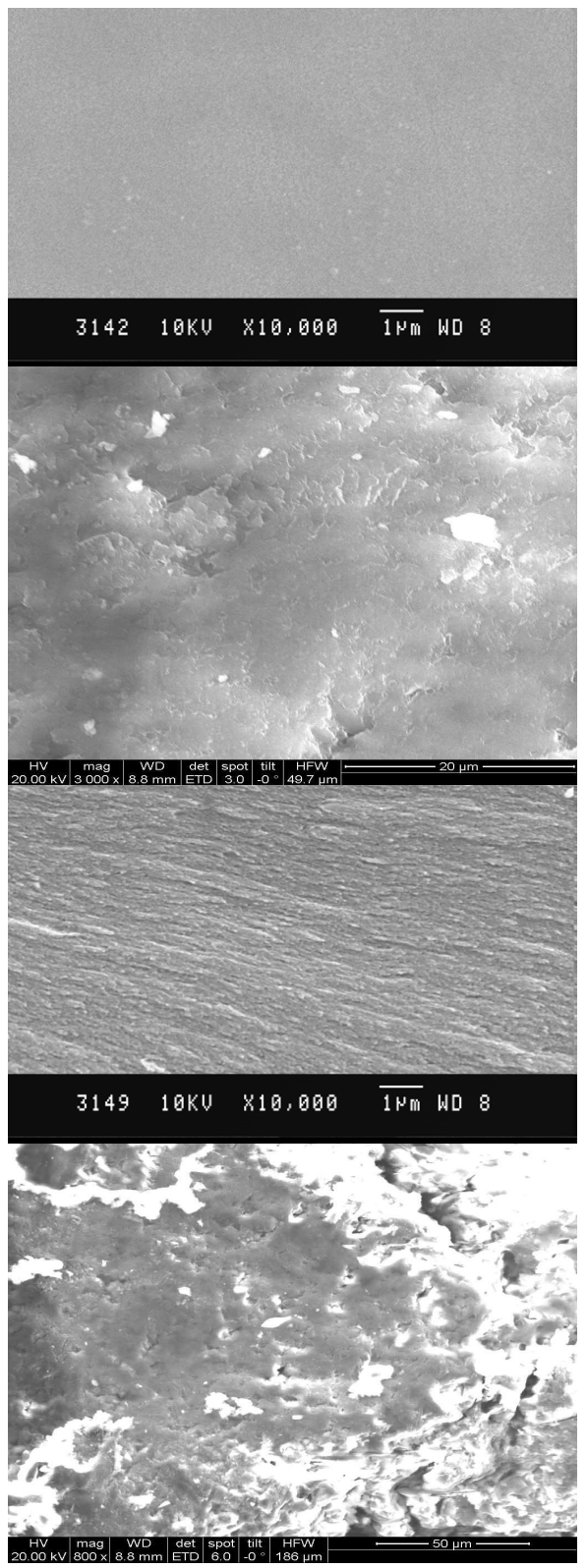

Fig-4: (a) Images showing micrographs obtained by using SEM for pure PF resin

SEM images of the surface morphology of pure phenol formaldehyde resin and CSF embedded resin material (b) were investigated by scanning electron microscopy SEM at $10 \mathrm{kV}$ with a JEOL (Japan) JSM-840A scanning microscope. All specimens were coated with a conductive layer $(400 \AA)$ of sputtered gold. Pure material showed a homogeneous surface and no characteristic change in morphology.
On introducing CSF, smooth surface was still observed along with the small white patches which indicate the presence of CSF content. The cross sectional surfaces of the same material were investigated in order to study details of the dispersion of CSF into resin matrix. The micrographs clearly show that CSF particles were dispersed uniformly throughout the resin matrix. As the loading of CSF increased the voids or white patches of CSF were more in the micrographs as shown in the figure below.

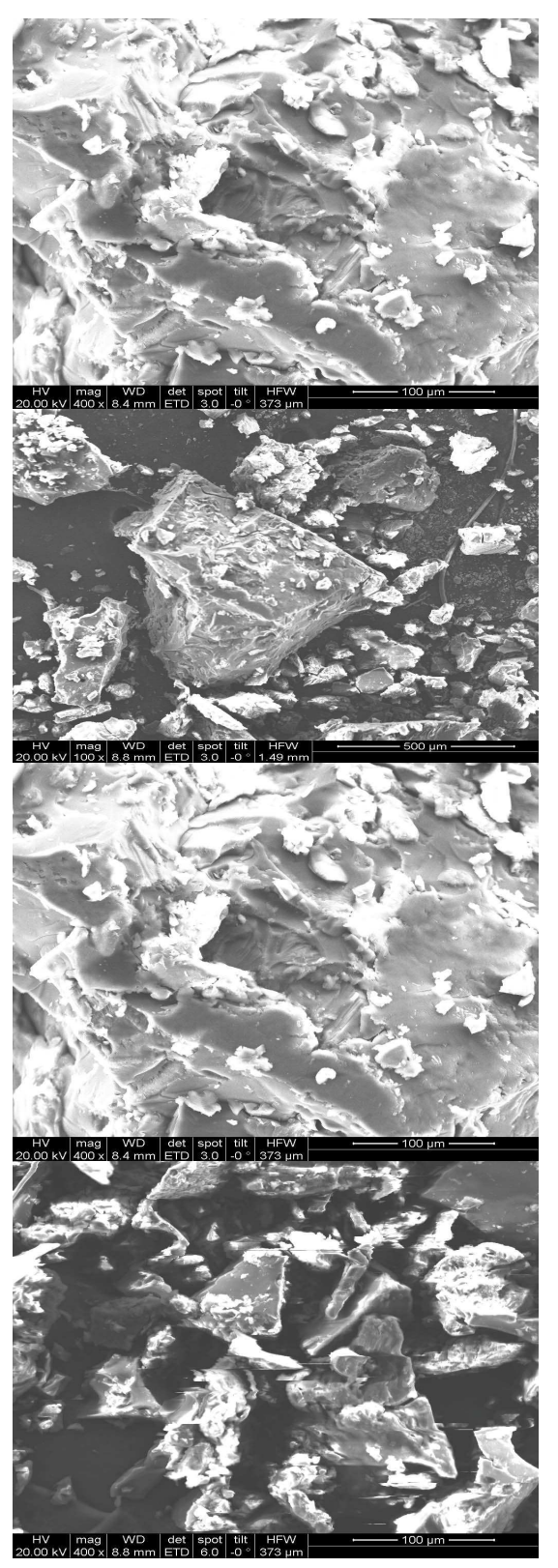

Fig-4: (b) Images showing SEM micrographs for CSF blended resin 


\subsection{Effect of pH on Polymerization time:}

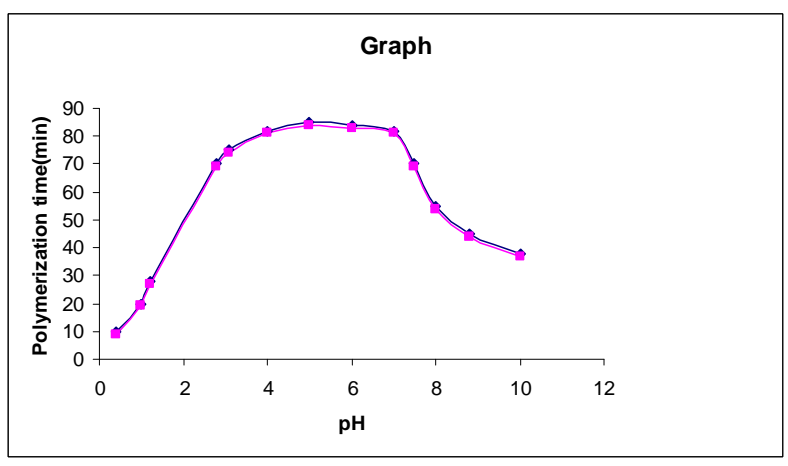

Fig-5: Polymerization time vs. pH values.

The alkaline catalyzed process depends on the temperature and also on the $\mathrm{pH}$. Polymerization time was determined by heating the known amount of resin, and it was found that the polymerization time increased by increasing the $\mathrm{pH}$. The $\mathrm{pH}$ of 4 was the point of lowest reactivity and is more common to increase the reactivity by raising $\mathrm{pH}$ by the addition of sodium hydroxide or other strong base.

\subsection{Effect of percentage of CSF on tensile strength:}

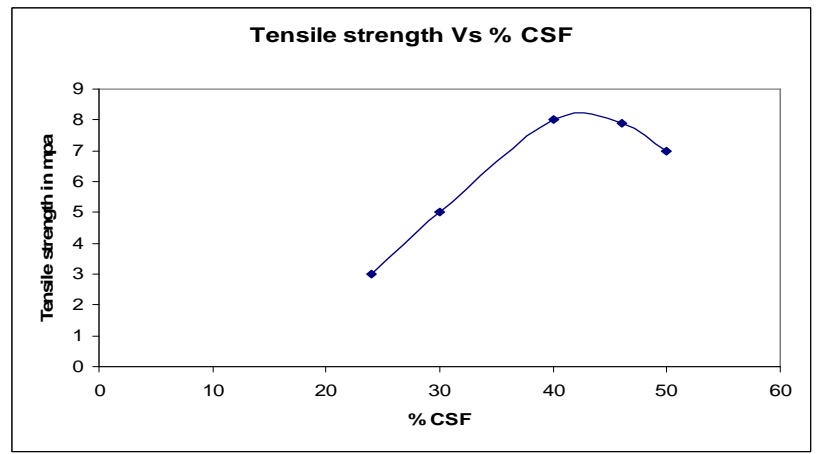

Fig-6: Percent CSF vs. tensile strength.

Tensile strength is one of the major characteristics of polymer. Good polymers show a very good tensile strength. When a plot of CSF embedded polymer versus tensile strength was studied, concentration of CSF i.e. $40 \%$ showed a good tensile strength.

It also showed good tensile strength at $45 \%$ concentration, while more the addition of CSF yielded less tensile strength.

\section{CONCLUSIONS}

Coconut shell flour CSF, is suitable as partial replacement for phenol. It takes less acid for its dispersion in the presence of phenol. The salts produced during subsequent processing are therefore less in this case. It should be advantageous to neutralize the sulphuric acid used for dispersing CSF. It can be dispersed with dilute alkali for reaction with formaldehyde. It also appears possible to replace a higher proportion of phenol than reported in this work with CSF. Assuming that the lignin and pentosans in the lignocellulosic materials take part in the resin forming reaction, the proportion of non-reacting cellulosic materials would be less in the case of CSF.

Resin adhesive prepared from CSF of particle size $-150+250$ was found to be suitable. Other resins prepared from varying CSF particle size were found unstable and had a very short pot life, hence these samples were rejected. The other particle sizes did not yield results that satisfy the properties of the original resin. In addition to the above, to manufacture 900 grams of resin, it costed Rs 9.89 . Hence to manufacture $1 \mathrm{~kg}$ of resin it costs around Rs 10.988. This is the cost of raw materials only not considering overheads. It can be concluded that $40-50 \%$ of phenol can be replaced by using CSF.

\section{SCOPE FOR FURTHER IMPROVEMENT}

The main component in PF resin adhesives is phenol, the cost of which significantly influences the cost of adhesives and consequently its application. Adhesives presently used by the plywood industry are predominantly synthetic resins almost entirely based on crude oil and natural gas. Among synthetic resin adhesives, phenol formaldehyde (PF) resins have been favored for the manufacture of plywood as the product is suitable for exterior use. Optimization of the cost, plywood industry requires continued availability of suitable adhesives at economically viable prices. So for the low price adhesive incorporating CSF, Sal powder, teak powder and other woody materials as replacements for phenol, which contain lignocellulosic materials, can be tried with.

It also appears possible to replace a higher proportion of phenol with CSF than reported in this work.

\section{ACKNOWLEDGEMENTS}

The authors are indebted to the Department of Material Science and Department of Physics, Indian Institute of Science, I.I.Sc Bangalore for providing invaluable support and facilities for testing the materials and products during the course of this work.

\section{REFERENCES}

[1] Dick Wood and Gray Linn, Plywood-their development, manufacture and application, 82-92.

[2] Irving Skiest, Handbook of Adhesives, 298-305.

[3] Indian Standards Institution IS: 303 Specifications for plywood for general purpose.

[4] I.P.I.R.I Journal, vol.5(2), 59-61, 1977. 
[5] Journal of Indian Academy of Wood sciences, vol.8 (2), 1977.

[6] Mc Cabe, Smith and Harriot, Unit Operations of Chemical Engineering, $5^{\text {th }}$ edn. McGraw Hill

[7] Robert Green, John H Perry, Chemical Engineers'

Handbook, $7^{\text {th }}$ edn, Mc Graw Hill. 